\title{
"Falar com seus botões": pelos meandros teóricos e empíricos das relações entre conversa interna, reflexividade e self
}

\author{
Amanda da Costa DaSilveira \\ Universidade Federal do Rio Grande do Sul \\ Mariane Lima DeSouza \\ Universidade Federal do Espírito Santo \\ William B. Gomes \\ Universidade Federal do Rio Grande do Sul
}

\begin{abstract}
Resumo
Este artigo tem dois objetivos. O primeiro é justificar a conversa interna como capacitação humana básica à reflexão e necessária à execução de tarefas complexas, conforme indicado por diferentes tradições de pesquisa. O segundo é interpretar o processo semiótico da conversa interna como expressão dialógica do self. A argumentação sustenta-se na lógica adutiva, do latim adducere, que é definida como trazer para prova ou consideração dados de diferentes fontes. Como resultado, a conversa interna é definida: 1) como fenômeno psicológico em seus próprios méritos, independente de metodologias ou teorias; 2) como processo para fazer sentido que pode ser chamado simplesmente de self; 3) como elo que esclarece as influências mútuas entre um self privado e o meio social, mas reconhecendo a autonomia funcional do self frente às forças sociais.

Palavras-chave: conversa interna; reflexividade; autoconsciência; self; lógica adutiva.
\end{abstract}

\begin{abstract}
"Talking with my buttons": the ins and outs on the theoretical and empirical relations among internal conversation, reflexivity and the self. This article has two objectives. First, it emphasizes the internal conversation as a basic human capacity for reflection that is necessary for the performance of complex tasks and decision making. Second, it interprets the internal conversation as a semiotic process for the dialogical expression of the self. The argument is based on an adductive logic, from the Latin adducere, which means to bring forward or consideration data from different sources. As a result, inner speech appears: 1) as a psychological phenomenon by its own conditions, independent of methodologies or theories; 2) as a process of meaning that we may call simply the self; 3) as a linking that clarifies the mutual influence between a private self and a social milieu, but recognizes the potential autonomy of the self toward the social forces.
\end{abstract}

Keywords: inner speech; reflexivity; self-awareness; self; adductive logic.

"Falar com seus botões" é expressão idiomática herdada do século XX na língua portuguesa e pouco observada no vocabulário dos jovens brasileiros atualmente. Em contraste, mais de 700.000 adulto-jovens usuários da ferramenta de relacionamentos online Orkut encontram-se, em 2007, associados a uma comunidade virtual intitulada "Eu falo sozinho". Em verdade, essa conversa que as pessoas empreendem com elas próprias tem despertado interesse desde a Grécia Antiga. Platão ( 400 a.C./1972), no Sofista, acreditava que o "diálogo interior e silencioso da alma consigo mesma" era sinônimo para o pensamento (p. 197-198). Quando as pessoas pensam sobre algo, frequentemente encontram-se engajadas na atividade de conversar aparentemente "sozinhas", o que parece ser uma característica inerente aos seres humanos. Conversa interna é a atividade de falar silenciosamente consigo mesmo (Morin, 2006). Essa definição continua a mesma desde as intenções segundas (reflexão) dos escolásticos (Lalande, 1996).

Nas últimas décadas, a literatura de língua inglesa abordou o fenômeno da conversa interna utilizando diversos termos: conversa para si mesmo (self-talk) (Morin \& Everett, 1990; Schneider, 2002; Siegrist, 1995), fala interna (inner speech) (DeSouza, DaSilveira, \& Gomes, 2008; Morin \& Everett, 1990; 
Wiley, 2006), diálogo interno (inner dialogue/internal dialogue) (Fernyhough, 2004; Wiley, 2006), monólogo (monologue) (Morin, 2006), enunciação (utterance) (Fernyhough, 2004; Flavell, Miller, \& Miller, 1993), frases para si ou frases do self (self-statements) e pensamentos automáticos (automatic thoughts) (Glass \& Arnkoff, 1997). Estudos publicados em língua portuguesa também abordam o fenômeno a partir de termos como fala egocêntrica (Piaget, 1923/1959), diálogo interior (DeSouza, 2005) e reflexividade (Domingues, 2002). No presente estudo, optou-se pelo uso do termo conversa interna, por se entender que esta é a tradução mais recorrente para inner speech, expressão que, por sua vez, mais aparece na literatura.

O presente artigo tem como objetivo fornecer um panorama geral do conceito e dos avanços já obtidos pelas pesquisas empíricas sobre a conversa interna e a reflexividade. $\mathrm{O}$ interesse epistemológico é demarcar uma região ontológica que é a capacitação humana para significar, gerar sentidos de curta ou longa duração: sobre si, sobre o outro, sobre o mundo e as respectivas relações. Por conseguinte, a argumentação privilegia evidências empíricas recolhidas por métodos e abordagens independentes, por entender ser este o melhor caminho para se excluir equívocos e interpretações falsas. A argumentação sustenta-se em uma lógica adutiva, do latim adducere, que é definida como trazer para prova ou consideração. Trata-se de recurso lógico para se estimar a condição de verdade de uma teoria, isto é, sua força preditiva ou sua falseabilidade. A condição de verdade de uma teoria depende tanto da sua consistência interna quanto da consistência com outros conhecimentos, teóricos ou empíricos.

A definição de lógica adutiva é a seguinte: “em diferentes contextos (regra), uma comparação externa (resultado), estabelece a identidade de dois fenômenos (caso)" (Lanigan, 1992, p. 217). Em outras palavras, a regra, como premissa ou hipótese, afirma que em diferentes contextos de investigação o resultado, isto é, a comparação de teorias (teste interno) e de evidências (teste externo), indicará a identidade ou não de dois ou mais fenômenos, isto é, a relação entre conversa interna e reflexividade.

A presente exposição abrange cinco diferentes contextos de investigação psicológica. O primeiro contexto é a formulação conceitual da conversa interna em uma perspectiva desenvolvimental concernente à relação entre linguagem e pensamento. O interesse é levantar a hipótese ontológica da conversa interna como função reflexiva. O segundo contexto é a utilização da conversa interna como ferramenta para pesquisa em aprendizagem e resolução de problemas. O interesse é saber como os passos para solução de um problema se articulam na conversa interna que se torna em conversa consigo mesmo no falar em voz alta. O terceiro contexto é a utilização de escalas e questionários em estudos sobre a relação entre conversa interna, autoconsciência e reflexividade. $\mathrm{O}$ interesse será para as enunciações dos itens destes instrumentos de pesquisa. $\mathrm{O}$ quarto contexto é o funcionamento cerebral, como revelado pelas pesquisas neuropsicológicas. O interesse é saber o que ocorre no cérebro quando a conversa interna está em atividade. O quinto contexto é a conversa interna como reflexividade ou self, essa capacidade humana de voltar o pensamento para um objeto, sendo esse objeto, um mim qualquer ou um mim mesmo, como argumentado por James (1890/1990) e Mead (1934). Concluiu-se com a revisão de dois estudos audaciosos que ousaram ultrapassar contextos e análises para se certificar a autonomia da função básica da reflexividade. Em suma, o argumento deste artigo é que funções psicológicas existem em si mesmas, independentes de teorias que nada mais são do que descrições ou metáforas de maior ou menor sucesso explicativo. A capacidade de gerar sentido ou self é uma dessas funções. $\mathrm{O}$ argumento da convergência empírica sustenta-se nas evidências de diferentes tradições de pesquisa apresentadas a seguir.

\section{Conversa interna e psicologia do desenvolvimento}

O reconhecimento da conversa interna e de sua importância para o desenvolvimento psicológico está presente nas obras clássicas de Jean Piaget (1896-1980) e Lev Vygotsky (18961934). Piaget $(1923 / 1959 ; 1924 / 1967)$ utilizou o termo "fala egocêntrica" para se referir à fala que as crianças emitem para si mesmas em situações de convívio social. Não haveria, nesta fala, preocupação alguma da criança se fazer entendida pelo outro. Vygotsky, estudando os primeiros experimentos de Piaget, provavelmente entre 1930 e 1934, observou que a fala egocêntrica seria uma forma de transição entre a fala exterior e interior (Vygotsky, 1998). Tal constatação agregava argumentos para sustentar a hipótese da origem social da linguagem (Vygotsky, 1934/1986). A transformação da fala exterior em interior (Vygotsky \& Luria, 1930/1993) passaria por quatro fases: (a) abreviação sintática - quando a conversa interna é experienciada como uma série de imagens verbais condensadas e fragmentadas; (b) predominância do sentido sobre o significado - quando a significância pessoal e privada das palavras na conversa interna predomina sobre os significados convencionais das palavras; (c) aglutinação - quando o desenvolvimento de palavras híbridas designa conceitos complexos específicos do sujeito na conversa interna; e (d) infusão de sentido - quando uma palavra na conversa interna se torna carregada de mais associações do que é inerente em seu significado convencional, adquirindo uma importância especial para o sujeito, não sendo compartilhada com as demais pessoas que usam a mesma palavra.

Recentemente, Fernyhough (2004) sugeriu um esquema de quatro níveis do desenvolvimento da conversa interna, com base nas propriedades semânticas que distinguem a conversa interna da externa enunciadas por Vygotsky e Luria (1930/1993). No nível 1 , chamado de diálogo externo, a criança e seu cuidador estão envolvidos em um diálogo aberto que mostra a conversa característica de "pergunta-e-resposta". No nível 2, da conversa particular, a criança dialoga para si mesma abertamente (e vai gradualmente subvocalizando esse diálogo). No nível 3, chamado de conversa interna expandida, a conversa particular está totalmente internalizada, mas o "pergunta-e-resposta" da conversa interna ainda é evidente, seguindo moldes semelhantes ao da conversa com o cuidador. Por fim, no nível 4, ou conversa interna condensada, as transformações sintáticas e semânticas sofridas na internalização produzem uma conversa interna que tem muito pouco (senão nada) daquela linguagem externa, e se tornou uma interação dialógica entre diferentes perspectivas 
da realidade; ou seja, refere-se ao estágio de pensar em seu significado puro, descrito por Vygotsky e Luria (1930/1993). Para Fernyhough (2004), o esquema é aplicável ao movimento que se pode realizar entre os níveis no pensamento humano em qualquer faixa etária. Para ele, sob condições de exigência cognitiva, pode-se realizar uma transição do nível 4 (conversa interna condensada em sua totalidade) para o nível 3 (conversa expandida) e até mesmo para o nível 2 (conversa particular dialógica): "é sob estas condições que nossa conversa interna é experienciada em um diálogo expandido, com todas as qualidades de uma conversa normal de pergunta-e-resposta" (Fernyhough, 2004, p. 56) ${ }^{1}$.

A conversa interna é um fato assumido pelos autores mencionados acima. Ela é descrita desde a iniciação, incluindo a transformação da conversa externa em interna, até a sua transformação em atividade altamente complexa que é o pensamento. A conversa ocorre por meio de uma linguagem condensada, com modificações sintáticas e semânticas. Em outras palavras, pensar é conversar internamente consigo mesmo, em linguagem própria. Tem-se assim a especificação de um campo ontológico: pensamento é uma conversa interna.

\section{Conversa interna como ferramenta na aprendizagem e na resolução de problemas}

No contexto de resolução de problemas, as ideias de Vygotsky forneceram a base teórica para o estudo experimental da conversa interna. Sokolov (1972) sugeriu que a conversa interna não implica na transformação de todos os pensamentos em palavras, mas se torna necessária quando a atividade mental se depara com problemas complexos. No entanto, a questão era como investigar a conversa interna em atividade. A saída encontrada foi a de resolver problemas, verbalizando em voz alta o que vinha a mente.

Bartl e Dörner (1998) investigaram a relação entre o número de perguntas verbalizadas na conversa interna em voz alta e o desempenho de uma tarefa. Os autores estudaram o caso de dois participantes que em um estudo anterior apresentaram estilos opostos de verbalização e de sucesso na resolução do problema. Eles denominaram de Logobene o participante que conseguiu resolver o problema proposto, e de Logomale o participante que não conseguiu resolver. Logobene resolveu a tarefa em 10 minutos, realizou 17 perguntas e produziu 126 enunciados. Em contraste, Logomale resolveu a tarefa em 30 minutos, fez a si mesmo apenas quatro perguntas e produziu 71 enunciados. Os autores concluíram que o maior número e a melhor qualidade de perguntas estavam associados ao sucesso na realização da tarefa.

Bertau (1999) solicitou a seis pessoas que resolvessem o Teste Matrizes Progressivas de Raven - TMPR (Raven, 1965), verbalizando cada passo para a resolução dos itens. Os resultados indicaram que a quantidade de conversa interna foi diretamente proporcional à dificuldade da tarefa proposta. A verbalização em voz alta da conversa interna obtida apresentou a abreviação sintática observada por Vygotsky (1934/1986) e por Fernyhough (2004). Os achados indicaram ainda que um melhor desempenho na transição da conversa interna condensada para sua forma dialógica aberta estaria relacionado a um sucesso maior do participante na resolução da tarefa. O estudo também encontrou possíveis vestígios estruturais de uma fala que fora socialmente internalizada, ainda na infância ou em um passado remoto.

Outras fontes para reconhecimento do fenômeno da conversa interna foram a psicoterapia e a Pedagogia. Psicoterapeutas utilizaram técnicas de controle da conversa interna infantil para tratamento de crianças com comportamentos impulsivos (Kendell \& Braswell, 1985). Educadores recorreram a técnicas de controle da conversa interna em voz alta para o aprimoramento do fluxo de pensamentos por meio de procedimentos de autoinstrução (Guerrero, 2004). Essas técnicas facilitavam o monitoramento direto do processamento cognitivo durante o desempenho de uma tarefa. Para Flavell, Miler, e Miler (1993) os educadores deveriam entender a conversa interna como uma atividade metacognitiva fundamental para o desenvolvimento da criança.

As pesquisas sobre aprendizagem e resolução de problemas trazem evidências convincentes da relação entre conversa interna e reflexividade, aqui redefinida como metacognição. Como apontou Vygotsky (1934/1986), a atividade cognitiva consiste na manipulação e no direcionamento objetivo e consciente de ferramentas psicológicas superiores: pensamento lógico, memória, atenção, procedimentos de tomada de decisão e resolução de problemas. Na mesma direção, Guerrero (2004) sugeriu que a conversa interna facilita a autorregulação do comportamento, auxiliando no controle dos processos que permitem que o indivíduo pense e monitore o processo de pensamento. Do ponto de vista epistemológico, o estudo da conversa interna na resolução de problemas trouxe duas importantes contribuições: mostrou como a mente resolve os problemas e como ocorre a conversa interna.

\section{Conversa interna e escalas de autoconsciência}

Autoconsciência é definida como atividade que o indivíduo dispõe de se tornar objeto de sua própria consciência (Morin, 2006). A autoconsciência pode ser acessada de três modos: 1) por recursos físicos, tais como espelhos, gravadores de voz, vídeos, que reflitam informações sobre o indivíduo; 2) por recursos sociais, tais como emissão de comportamentos e da observação de suas reações, incluindo feedback de outros indivíduos; e 3) por conversa interna (Morin \& Everett, 1990). Das três, a conversa interna é o principal meio para o estudo e a compreensão da autoconsciência (Morin, 2002). Deste modo, a conversa interna serviu de base para a construção de escalas e questionários para o estudo da autoconsciência.

Fenigstein, Scheier, e Buss (1975) elaboraram uma escala para avaliar variações de autoconsciência nos indivíduos, denominada de Escala de Autoconsciência, validada no Brasil por Teixeira e Gomes (1995). A escala é composta por três subescalas: 1) Autoconsciência Pública ("Eu me preocupo com a maneira como me apresento"), 2) Autoconsciência Privada ("Eu estou sempre tentando me entender"), e 3) Ansiedade Social ("Eu levo tempo para vencer minha timidez em situações novas"). Estudos que utilizaram a escala sugeriram que indivíduos com maiores escores de autoconsciência apresentaram as seguintes características: 1) monitoram e modificam seus comportamentos de forma mais eficaz; 2) sentem emoções mais intensamente; 3 ) comportam-se de forma mais consistente com suas atitudes; 4) 
conformam-se menos com a pressão social; e 5) reagem mais fortemente à rejeição social.

Foram vários os estudos que desenvolveram ou utilizaram escalas para estimar a relação entre autoconsciência e conversa interna. Siegrist (1995), na Alemanha, desenvolveu a Scale for Inner Speech - SIS, com itens como os exemplificados a seguir: "Em situações difíceis eu digo algumas vezes para mim mesmo, 'você pode fazer isso', 'você pode fazer isso muito bem"'. A correlação entre a Scale for Inner Speech e a Escala de Autoconsciência foi de 0,48 (Siegrist, 1995). Schneider (2002) encontrou uma correlação ainda maior $(0,51)$, comparando dados de versão reduzida da Scale for Inner Speech - SIS (Siegrist, 1995) com a Escala de Autoconsciência Privada, de Fenigstein et al. (1975). O autor interpretou os resultados como medida de autorreflexão. Esses estudos sugerem que, quando mais a pessoa enfoca em si mesma, mais ela conversa internamente sobre aspectos privados.

A reação à Escala de Autoconsciência (Fenigstein et al., 1975) veio de Trapnell e Campbell (1999). Esses autores reanalisaram dados obtidos pela Escala de Autoconsciência e mostraram que autoconsciência não representa um constructo unitário de voltar a atenção para si, sempre com as mesmas qualidades. O foco em si mesmo pode produzir movimentos reflexivos construtivos nos quais se esclarecem noções e problemas, mas pode também fechar-se em movimentos circulares estereotipados. Tais autores diferenciaram as duas modalidades de focos sobre si como reflexivo e ruminativo, cada modalidade levando a diferentes consequências cognitivas e comportamentais.

A distinção entre foco reflexivo e ruminativo tem-se mostrado útil para explicar uma aparente incongruência em achados de pesquisa: o chamado paradoxo da autoabsorção. No paradoxo, indivíduos com altos escores de autoconsciência deveriam apresentar melhor ajustamento psicológico quando comparadas a pessoas com baixos escores de autoconsciência (Trapnell \& Campbell, 1999). Contudo, na revisão de literatura desses autores, muitas pesquisas apresentaram evidências de que altos escores de autoconsciência estavam associados a problemas psicológicos, tais como depressão, baixa autoestima e ansiedade.

Desse modo, ao reconhecer a natureza dual da atenção voltada para si, Trapnell e Campbell (1999) sugeriram uma diferença entre reflexão sobre si e ruminação. Reflexão é um modo produtivo de articular o pensamento, enquanto ruminação é um produto indesejado no pensamento do indivíduo. Os autores demarcaram os dois focos atentivos com o Questionário de Reflexão e Ruminação (QRR) (Trapnell \& Campbell, 1999). Um exemplo típico de reflexão é o item que segue: "Eu gosto de meditar sobre a natureza e o significado das coisas". Em contraste, os itens de ruminação trazem enunciados como o que segue: "Eu sempre pareço estar remoendo, em minha mente, coisas recentes que eu disse ou fiz". O QRR já foi traduzido e validado para o português (Zanon \& Teixeira, 2006).

Trapnell e Campbell (1999) foram felizes na distinção de dois focos atentivos, mas infelizes em denominá-los de reflexão e de ruminação. Cabe aqui relembrar a definição clássica de reflexão como o pensamento voltado sobre si mesmo e argumentar que, seja essa articulação produtiva, improdutiva ou, mesmo, anormal, sempre será uma atividade reflexiva. De qualquer modo, os focos atentivos apontados são modalidades de conversa interna.

Sabe-se que questionários e escalas trazem escolhas de contexto a priori, ou seja, os itens são prejulgamentos dos pesquisadores, dados como opções restritas aos potenciais respondentes. No entanto, essas dificuldades são contrabalançadas pelos cuidados psicométricos e pela confrontação com instrumentos similares. Os contextos a priori constituídos pelas diferentes escalas mencionadas configuram um movimento no qual se parte da conversa interna para a formulação de itens sobre autoconsciência, avançando gradativamente para itens que se referem diretamente à conversa interna. Esse movimento é muito claro na comparação dos itens das diversas escalas mencionadas. Os estudos com escalas e questionários também levantaram a questão do movimento não unitário da autoconsciência, como manifesto na função reflexiva.

O reconhecimento da conversa interna pela psicometria, uma tradição tão forte em Psicologia, é mais uma evidência convergente para a demarcação ontológica do fenômeno. As pesquisas com questionários contribuíram com a distinção entre diferentes modos de autoconsciência e reflexividade, e com evidências empíricas para a relação entre conversa interna e reflexividade.

\section{Conversa interna: aspectos neuropsicológicos}

Um reconhecimento promissor do fenômeno da conversa interna, em outro registro empírico, vem dos estudos de neuropsicologia. Nesses estudos, o fenômeno da conversa interna surge associado ao desempenho de tarefas neuropsicológicas e as informações obtidas por neuroimagem (DeSouza, 2005). Com base em uma série de estudos com substrato neural, Morin (2002, 2006) sugeriu que a conversa interna está associada à atividade do hemisfério cerebral esquerdo e, por conseguinte, intimamente relacionada à autoconsciência. Ela é acionada quando algumas áreas do giro frontal inferior esquerdo estão em atividade. A capacidade autoarticulatória verbal do hemisfério esquerdo opera tanto para guiar o comportamento quanto para compreender o impacto de tal comportamento no mundo físico e no mundo social. Isto explica o desenvolvimento gradual da autoconsciência (Morin, 2002). Porções do lobo pré-frontal esquerdo estão tanto associadas com atividades de autorreflexão quanto de conversa interna, estando a articulação da conversa interna associada à clareza da autoconsciência (Morin, 2002). Pacientes que sofreram alguma lesão cerebral apresentam déficits de autoconsciência, mesmo que tais lesões sejam nas áreas préfrontais direitas, que não estão associadas à conversa interna. Esses achados reafirmam a natureza multifatorial e sistêmica da autoconsciência (Morin, 2006).

Estudos de desempenho de tarefas neuropsicológicas relacionados à conversa interna utilizaram tarefas de autodescrição e/ou autorreconhecimento (Keenan, Nelson, O'Connor, \& Pascual-Leone, 2001; Kircher, Brammer, Simmons, Bartels, \& David, 2002). Os instrumentos utilizados foram Tomografia de Emissão de Pósitrons (PET), Imagens de Ressonância Magnética Funcional (fMRI) e mensuração de potencial motor evocado. Achados neuropsicológicos sobre 
desempenho de tarefas têm sido interpretados com base em um modelo proposto por Baddeley, em 1986 (Baddeley, Chincotta, \& Adlam, 2001; Miyake, Emerson, Padilla, \& Ahn, 2004). Neste modelo, a conversa interna é associada ao sistema da alça fonológica (Baddeley et al., 2001) que é considerada um sistema independente periférico (escravo) da memória de trabalho, regulada por uma estrutura de controle central (o executivo central) e especializada no armazenamento a curto prazo e no processamento das informações verbais. Um dos seus subcomponentes, chamado de processo de controle articulatório, está especialmente relacionado à geração da conversa interna. Contudo, a conversa interna envolve conexões cerebrais mais extensas (Kircher et al., 2002). De interesse para presente análise é o rastreamento de substratos neurais associados à autoconsciência (condição de disponibilidade à experiência), à autorreflexão (pensar sobre os próprios pensamentos) e à conversa interna (a própria atividade de autorreflexão). Essas evidências demarcam a empiria a qual se focaliza como ontologia de acesso reconhecível e replicável.

\section{Conversa interna e self}

Self é um conceito por demais conhecido na Psicologia. Inclui desde o amplo campo da consciência a aspectos mais delimitados como consciência de si, sentido de si e o próprio eu. O termo self usado como substantivo carrega dois sentidos: 1) de si e 2) por si próprio. Como elemento de composição, self corresponde na língua portuguesa ao antepositivo auto, por exemplo, autoestima, autoconceito ou autoeficácia, referindose a aspectos de si mesmo: o quanto eu me estimo ou o quanto eu sou eficaz.

Wiley (1994) abordou o conceito de self em uma perspectiva semiótica, definindo-o de um modo genérico para indicar um ser humano, pessoa, indivíduo, sujeito ou agente com a característica da ação cognoscitiva: racional, simbólica, abstrata, e linguística. Dito simplesmente, o self é a condição humana de ser reflexiva. Por conseguinte, a ação reflexiva é dialógica, manifestando-se na forma de uma conversa interna. Wiley (1994) argumentou e procurou demonstrar que o diálogo ocorre entre três aspectos, partes, papéis ou agências temporais do self: o passado "Mim", o presente "Eu" e o futuro "Você". Na relação dialógica, o "Eu" (presente) fala com o "Você" (futuro) sobre o "Mim" (passado). Apenas o self presente ("Eu") pode falar, enquanto o "Você" e o "Mim" só podem ouvir e ser objeto da fala.

Wiley (1994) chamou esse esquema de conversa interna de modelo Peirce-Mead, por se tratar de uma síntese das ideias propostas pelos dois pensadores. A polaridade "Eu" - "Você" é tomada de Peirce, ao passo que o "Eu" - "Mim" vem de Mead. Para Peirce (CP 5.412) "uma pessoa não é um indivíduo de modo absoluto. Seus pensamentos são o que ela está dizendo para si mesma, ou seja, dizendo para esse outro self que está acabando de chegar no decurso do tempo". Por sua vez, Mead (1934, p. 335) dizia que "pensar é simplesmente o raciocínio de um indivíduo, o desenrolar de uma conversa entre o que denominei de 'eu' e de 'mim"," Resumindo, para Peirce a conversa interna tinha uma função interpretativa, ocorrendo do "Eu" para o "Você", do presente para o futuro. Para Mead, a conversa interna tinha uma função reflexiva, ocorrendo do "Eu" para o "Mim", do presente para o passado. A combinação das teorias de Peirce e Mead, ampliando a relação para presente, passado e futuro, acentuou a condição comunicativa do self dialógico, nas funções de reflexão e de interpretante. Wiley (1994) integrou as duas teorias, pois mesmo tratando-se de dois pragmatistas americanos, raramente foram estudados comparativamente.

As evidências empíricas de Wiley (1994) procedem de excertos de conversa interna obtidos em diferentes situações em que pessoas falavam sozinhas. Por exemplo, o autor insere o texto de uma secretária que fala sozinha ao se dirigir para o trabalho, ou, ainda, a transcrição da fala de um estudante durante o sono. O instrumento de análise de Wiley para estas conversações é resumido no que ele chamou de estrutura da conversa interna, que é uma espécie de matriz, em que na linha horizontal estão: 1) os participantes básicos "Mim", "Eu”, "Você"; 2) os participantes visitantes, temporários ou permanentes (pessoas reais mais próximas ou distantes) que na conversa assumem o lugar de "Você" (futuro), mas falam do presente; e 3) as manifestações involuntárias inconscientes. Na linha vertical estão os perfis de cada participante, diferenciados pelo tempo de conjugação (presente, passado ou futuro), pela condição de objetividade ou subjetividade (por exemplo, o "Mim" é objetivo, o presente é subjetivo, e o "Você" é subjetivo e objetivo), e pela condição de determinação ou liberdade (por exemplo, o "Mim" não é livre, o "Eu" é livre, e o "Você" é livre e não livre (ver Wiley, 1994). A matriz mostra a extensão da conversa interna, como uma estrutura aberta e ambivalente, isto é, entre o determinado e o indeterminado, entre a temporalidade do "Mim", "Eu" e "Você", e a atemporalidade do não consciente (Tabela 1).

O self dialógico e semiótico de Wiley (1994) contempla tanto o entendimento conteudista tradicional da Psicologia, por exemplo, self estima, identidade do self, ou self ideal, como ressalta a condição cognitiva processual do self: produção de sentido sobre si (self-concept), sobre o mundo (o que se interpreta do que percebe ou imagina a cada instante), ou da relação entre si e o social (identidades). O conceito de self semiótico pode ser mais bem compreendido a partir da suposição de que, se a cognição de qualquer objeto é mediada por signos, então o mesmo ocorre na cognição do indivíduo que pensa sobre si mesmo. A condição de produzir signo é uma condição humana universal e, portanto, evolucionária.

O signo enquanto tal é um fenômeno cultural e está na base da constituição do senso de si mesmo individual. Em um estudo mais recente, Wiley (2006) reforça a importância do fenômeno da conversa interna como o próprio sentido de si (self), isto é, dessa capacidade que o indivíduo tem de se gerar significados constantemente. Os significados, por sua vez, são constituídos a partir de relações mediadas com sistemas de signos, herdados socialmente. Assim, na formulação semiótica, a fonte do conhecimento sobre si mesmo não está nos processos fisiológicos que informa sobre as condições de morfologia e funcionamento, nem na introspecção que na verdade é uma retrospecção. A fonte do conhecimento está no pensamento objetivado nos signos e veiculados pela conversa interna. Os signos que constituem a conversa interna carregam a marca do mundo social e da cultura, mas se distinguem pela originalidade da formulação e da perspectiva que nasce de um sujeito corporificado e situado. 
Tabela 1

Estrutura da Conversa Interna

\begin{tabular}{|c|c|c|c|c|c|c|}
\hline $\begin{array}{ll}\text { Participantes } & \text { Perfis } \\
\end{array}$ & Mim & $\mathrm{Eu}$ & Você & $\begin{array}{l}\text { Visitantes } \\
\text { temporários }\end{array}$ & $\begin{array}{l}\text { Visitantes } \\
\text { permanentes }\end{array}$ & $\begin{array}{c}\mathrm{O} \\
\text { inconsciente }\end{array}$ \\
\hline Pessoa & Primeira & Primeira & Segunda & Segunda & Segunda & Terceira \\
\hline Tempo & $\begin{array}{l}\text { Passado (e } \\
\text { Atemporal) }\end{array}$ & Presente & Futuro & Presente & Presente & Atemporal \\
\hline Caso & Objetivo & Subjetivo & $\begin{array}{l}\text { Subjetivo } \\
\text { e objetivo }\end{array}$ & $\begin{array}{l}\text { Subjetivo e } \\
\text { objetivo } \\
\text { Mais livre }\end{array}$ & Objetivo & Todos \\
\hline $\begin{array}{l}\text { Liberdade/ } \\
\text { Determinismo }\end{array}$ & Não livre & Livre & $\begin{array}{l}\text { Não livre } \\
\text { e livre }\end{array}$ & $\begin{array}{l}\text { do que os } \\
\text { visitantes } \\
\text { permanentes }\end{array}$ & Não livre & Determinado \\
\hline $\begin{array}{l}\text { Relação com o outro } \\
\text { generalizado }\end{array}$ & Aliado & Distante & $\begin{array}{l}\text { Aliança } \\
\text { diminuída }\end{array}$ & $\begin{array}{l}\text { Menos } \\
\text { aliado do } \\
\text { que os } \\
\text { visitantes } \\
\text { permanentes }\end{array}$ & $\begin{array}{l}\text { Aliado e } \\
\text { constitutivo }\end{array}$ & Livre \\
\hline $\begin{array}{l}\text { Disponibilidade cognitiva do } \\
\text { Eu }\end{array}$ & Objeto & $\begin{array}{l}\text { Ponto } \\
\text { cego }\end{array}$ & Cossujeito & Cossujeito & $\begin{array}{l}\text { Cossujeito, } \\
\text { mas } \\
\text { sedimentado } \\
\text { no outro } \\
\text { generalizado }\end{array}$ & $\begin{array}{l}\text { Velado pela } \\
\text { barreira } \\
\text { semiporosa } \\
\text { da } \\
\text { linguagem }\end{array}$ \\
\hline
\end{tabular}

A abordagem pragmatista e semiótica de Wiley (1994) vem estimulando a realização de estudos empíricos sobre conversa interna, com atenção aos elementos comunicacionais envolvidos. Archer (2003) dedicou ao fenômeno conversa interna um volume de 370 páginas, no qual apresenta uma pesquisa qualitativa realizada com 20 participantes, usando, para tanto, entrevistas em profundidade. Na visão sociológica realista da autora, o problema central da teoria social é a relação entre estrutura (sociedade) e agência (sujeitos). A preocupação volta-se para as relações entre sociedade e sujeitos, e para a ideia dominante nos últimos anos, que subjugou a emergência do sujeito ao social. $\mathrm{Na}$ crítica da autora, esse modo de entendimento é determinista e aniquila o sujeito, negando a capacidade individual de escolhas e de ação diante da sociedade. Na pesquisa, o sujeito apresentouse não como um efeito, mas como um agente ativo que pode mudar o curso de suas ações e das relações com a sociedade. Foi o que indicou perguntas simples como "o que devo fazer agora?", com respostas do tipo "essa foi a minha escolha". Pode-se questionar a epistemologia de Archer por não atentar para possíveis influências de ações inconscientes decorrentes do convívio social. Contudo, Archer argumenta que o agente responde ao social por meio da conversa interna ou deliberação reflexiva que é falível e corrigível, intencional e diferenciada. A conversa interna é uma propriedade pessoal irredutível e, portanto, real, acarretando efeitos causais. Está aí a relação entre o pragmatismo de Peirce e o realismo de Archer. A clareza realista de Peirce estava na sua lógica semiótica, ao dizer que a consciência não atribuía sentido aos signos, pois os signos tinham sentido em si mesmo.

O método de análise qualitativa de Archer (2003) foi de levantamento e aglutinação temática, constituída pelas convergências e divergências das falas captadas. A autora distinguiu três modalidades de conversa interna, categorizadas como: 1) comunicantes reflexivos, 2) autônomos reflexivos, e 3) metarreflexivos. Na primeira estão aqueles que se sentem inseguros sobre os juízos resultantes da própria reflexão, recorrendo ao diálogo com outros. No segundo estão aqueles que a reflexão é de domínio pessoal e não está aí para ser compartilhada por outros. Na terceira estão aqueles que colocam em análise os próprios atos reflexivos. As três modalidades de conversa interna sugerem três perfis de agência, com possíveis e até previsíveis desdobramentos na relação com o social. No entanto, os resultados da pesquisa também indicaram agentes que não se encaixavam em nenhuma das três modalidades. Esse perfil foi denominado de reflexividade fraturada. Os estudos de Archer (2007) prosseguiram com o desenvolvimento de uma escala: o Indicador de Conversa Interna (Internal Conversation IndicatorICONI), para confirmar e refinar os achados qualitativos de Archer (2003).

A interpretação semiótica da conversa interna contribui não somente com um modelo estrutural de ação, a forma triádica básica na qual se constitui a conversação (o "Eu" que fala para o "Você" sobre o "Mim"), mas demonstra a pertinência da função reflexiva nas deliberações cotidianas. A conversa interna parece esconder as intricadas e enigmáticas relações entre aquele que delibera e o social que constitui a base, mas pode ser transformado por aquele que delibera e o seu reverso.

\section{A articulação entre contextos de pesquisa empírica sobre conversa interna}

A presente exposição é um esforço adutivo para reunir resultados de investigações independentes e paralelas sobre um dado fenômeno: conversa interna ou reflexividade. $\mathrm{O}$ argumento está baseado na premissa semiótica de que signos têm sentido em si mesmo. Na semiótica de Charles Peirce, todos os fatos humanos e não humanos se reduzem a signos, a sinais que apontam para outros sinais. Neste sentido, a conversa interna foi tomada como signo ou fenômeno universal da natureza humana $\mathrm{e}$, portanto, com poder em si mesmo, cabendo à pesquisa combinar esta função natural e evolucionária de geração de sentido, com a função cultural e simbólica de especificação de sentidos. Nas palavras de Peirce: 
O presentacionista afirma que a percepção é uma consciência de dupla face na qual o percepto aparece agindo forçosamente sobre nós, de modo que na percepção a consciência de um objeto ativo e de um sujeito reativo é tão indivisível quanto o senso de exercício é correlato e inseparável do senso de resistência, quando se faz um esforço muscular. (CP 5.607)

Com efeito, a ordem dos argumentos apresentados contraria valores subjacentes de epistemologias equidistantes, nas quais fenômenos estão associados ou são gerados por teorias. Ocorre que teorias também precisam ser testadas em comparação umas com as outras. Neste estudo, foram percorridos cinco contextos de investigações nos quais o fenômeno da conversa interna foi reconhecido e descrito em seu percurso afirmativo e desenvolvimental; reavaliado e flexibilizado como recurso estratégico para solução de problemas; utilizado e referido como base para a construção de escalas sobre autoconsciência e reflexividade. A conversa interna foi ainda acompanhada como atividade cerebral e definida como função interpretativa e deliberativa. As considerações avançaram um pouco mais e redefiniram o self para além de produtos (autoestima, autoconceito), isto é, o self como função reflexiva genérica e geral. Nestes termos, a conversa interna é a operacionalidade da reflexão e a dialogicidade do self.

A presente exposição estaria incompleta se não avançasse um pouco mais e trouxesse pesquisas que reúnem, ao menos, alguns dos contextos mencionados. Deste modo, os estudos apresentados à guisa de conclusão reúnem os contextos de solução de problemas em voz alta, escalas e questionários, e self semiótico. DeSouza (2005), seguindo a orientação semiótica e triádica de Peirce, estudou a conversa interna verbalizada, utilizando a técnica de Bertau (1999): resolução do Teste Matrizes Progressivas de Raven (TMPR) em voz alta. Dezoito adultos participaram do experimento. $\mathrm{O}$ foco não era a resolução do Raven, mas a verbalização das respostas em voz alta. A análise qualitativa das transcrições sustentou-se na tradição fenomenológica de pesquisa (Gomes, 1998), restringindo-se, contudo, ao exame intuitivo da relação sinérgica entre a descrição fenomenológica (a síntese do que foi verbalizado) e a análise indutiva (a definição propositiva do que foi percebido como conversação interna verbalizada). Como resultado, definiu-se a estrutura fenomenal das respostas em três categorias: 1) descrição visual, na qual os participantes descreviam as configurações gráficas do TMPR; 2) raciocínio lógico, no qual os participantes verbalizavam a possível sequência lógica que estava por trás da resolução do problema proposto no TMPR; e 3) diálogos, nos quais os participantes formulavam respostas para suas próprias perguntas. A conversa interna atravessou todas as manifestações diante do problema. Contudo, aqueles enunciados classificados como pertencentes às duas primeiras categorias (descrição visual e raciocínio lógico) expressavam um nível informacional da conversa interna, isto é, redução da incerteza. Em contraste, os diálogos evidenciaram a qualidade comunicacional do fenômeno, isto é, constituição de certeza. A diferenciação entre informação e comunicação é perspicaz porque destaca a presença de diferentes vozes ou posições na conversação interna. $\mathrm{Na}$ informação tem-se uma conversa interna bidimensional, isto é, só uma voz é que fala. Na comunicação tem-se uma conversa interna tridimensional, isto é, há um conjunto de vozes que falam e respondem (ver DeSouza et al., 2008).

A replicação do estudo por DaSilveira (2007) confirmou as três estruturas fenomenais (descrição visual, raciocínio lógico e diálogos) encontradas por DeSouza (2005). Contudo, a grande surpresa do experimento veio com as duas variações introduzidas por DaSilveira (2007). A primeira foi a introdução de um novo contexto, solicitando aos participantes que também respondessem a um questionário sobre reflexão e ruminação. A segunda variação foi analisar em conjunto dados originados em dois diferentes contextos: as propriedades métricas da aplicação da técnica Bertau/TMPR e do Questionário de Reflexão e Ruminação (Zanon \& Teixeira, 2006). Foi possível, então, identificar sete casos extremos, com base no tempo de duração, número de palavras e número de acertos no TMPR, e combiná-las com escores de alta ruminação e baixa reflexão, e de alta reflexão e baixa ruminação. Com esses dados em mãos, DaSilveira (2007) retornou às transcrições das conversas internas e constatou que as três categorias de respostas fenomenais ora se concentravam no objeto da tarefa, ora no sujeito que respondia a tarefa. $\mathrm{Na}$ interpretação da pesquisadora, a ruminação e a reflexão eram constructos cuja evidência não pertencia à forma e, sim, aos conteúdos veiculados pela conversa interna. Obtém-se, então, que conversa interna está por trás tanto da resolução de problemas cotidianos, quanto do processo de autoconsciência, em que o self representaria o problema e a informação sobre o self seria a solução (autoconhecimento) (Morin, 2006).

\section{Conclusão}

Para os pragmatistas americanos clássicos, como Peirce e Mead, a conversa interna é considerada parte da própria natureza do self (Wiley, 2006). Ou seja, é responsável por viabilizar as habilidades semióticas e simbólicas dos seres humanos e lhes permite, por conseguinte, conciliar a consciência de eventos e entidades a partir de uma perspectiva individual em um determinado momento de sua existência. Para o realismo social de Margaret S. Archer, a conversa interna apresenta-se como a empiria na qual se poderá esclarecer as intrincadas relações entre estrutura (social) e agência (individual).

Ainda que dezessete anos tenham se passado desde que Morin e Everett (1990) expuseram a necessidade de se explorar a relação causal entre conversa interna e autoconsciência, muito poucas pesquisas empíricas foram realizadas nessa área. Isso talvez ocorra justamente pela dificuldade de se obter dados experimentais relacionados à conversa interna. As pesquisas neuropsicológicas, fortemente beneficiadas com os avanços das técnicas de neuroimagem, poderão contribuir para o conhecimento das relações entre os processos cerebrais e as atividades psíquicas.

Em síntese, a conversa interna é uma relação rotineira, simbolicamente mediada, do indivíduo com ele mesmo. A sintaxe da conversa interna é própria para cada indivíduo, não estando vinculada à linguagem externa. A conversa interna é o mesmo que reflexividade, isto é, cognição prática e produção simbólica em geral (Domingues, 2002). Em todas as suas formas, 
a conversa interna apresenta-se como mediação entre o mundo interno e o externo, objetivando o conhecimento de aspectos da vida individual por meio de formas de expressão culturalmente compartilhadas. Sua dimensão multifuncional sublinha a importância da temática nos estudos do comportamento e do pensamento e da sua interação no mundo. Os vários contextos de investigação não tiveram forças suficientes para dar o destaque que é devido à pesquisa e à aplicação da conversa interna. Deste modo, em comparação com outros conceitos centrais da Psicologia, o estudo da conversa interna ainda permanece negligenciado não apenas na pesquisa, mas também nos manuais de neurolinguística e de introdução à Psicologia.

\section{Referências}

Archer, M. (2003). Structure, agency and the internal conversation. Cambridge: Cambridge University Press.

Archer, M. (2007). Making our way through the world: Human reflexivity and social mobility. Cambridge: Cambridge University Press.

Baddeley, A. D., Chincotta, D., \& Adlam, A. (2001). Working memory and the control of action: evidence from task switching. Journal of Experimental Psychology: General, 130, 641-657.

Bartl, C., \& Dörner, D. (1998). Sprachlos beim Denken. Sprache \& Kognition, 17(4), 224-238.

Bertau, M. C. (1999). Spuren des Gespraechs in innerer sprache. Versuch einer analyse der dialogischen anteile des lautes denkens. Zeitchrift für Sprache \& Kognition, 18(1/2), 4-19.

DaSilveira, A. C. (2007). Conversação interna: entre a reflexividade e a ruminação (Dissertação de mestrado, Universidade Federal do Rio Grande do Sul, Porto Alegre)

DeSouza, M. L. (2005). Self semiótico e self dialógico: um estudo do processo reflexivo da consciencia (Tese de doutorado, Universidade Federal do Rio Grande do Sul, Porto Alegre).

DeSouza, M. L., DaSilveira, A. C., \& Gomes, W. B. (2008). Verbalized inner speech and the expressiveness of self-consciousness. Qualitative Research in Psychology, 5, 154-170.

Domingues, M. J. (2002). Reflexividade, individualismo e modernidade. Revista Brasileira de Ciências Sociais, 17(49), 55-70.

Fenigstein, A., Scheier, M. F., \& Buss, A. H. (1975). Public and private selfconsciousness: assessment and theory. Journal of Consulting and Clinical Psychology, 36, 1241-1250.

Fernyhough, C. (2004). Alien voices and inner dialogue: towards a developmental account of auditory verbal hallucinations. New Ideas in Psychology, 22, 49-68.

Flavell, J. H., Miler, P. H., \& Miler, S. A. (1993). Cognitive Development. New Jersey: Englewood Cliffs.

Glass, C. R., \& Arnkoff, D. B. (1997). Questionnaire methods of cognitive self-statement assessment. Journal of Consulting and Clinical Psychology, 65(6), 911-927.

Gomes, W. B. (1998). A entrevista fenomenológica e o estudo da experiência consciente. In W. B. Gomes (Org.), Fenomenologia e pesquisa em psicologia (pp. 19-44). Porto Alegre: Editora da Universidade Federal do Rio Grande do Sul.

Guerrero, M. C. M. (2004). Early stages of L2 inner speech development: what verbal reports suggest. International Journal of Applied Linguistics, 14(1), pp. 90-112.

James, W. (1990). The principles of psychology. Chicago: Encyclopaedia Britannica. (Original publicado em 1890)
Keenan, J. P., Nelson, A., O’Connor, M., \& Pascual-Leone, A. (2001, janeiro). Self-recognition and the right hemisphere. Nature, 409, 305.

Kendell, P. C., \& Braswell, L. (1985). Cognitive behavior therapy for the impulsive children. New York: Guilford Press

Kircher, T. T. J., Brammer, M. J., Simmons, A., Bartels, M., \& David, A. S. (2002). The neural correlates of intentional and incidental self processing. Neuropsychologia, 40, 683-692.

Lalande, A. (1996). Vocabulário técnico e crítico de Filosofia. (F. S. Correia, M. E. V. Aguiar, J. E. Torres, \& M. G. Souza, Trads.). São Paulo: Martins Fontes.

Lanigan, R. (1992). The human science of communicology. Pittsburgh: Duquesne University Press.

Mead, G. H. (1934). Mind, self and society. Chicago: University of Chicago Press.

Miyake, A., Emerson, M. J., Padilla, F., \& Ahn, J. C. (2004). Inner speech as a retrieval aid for task goals: the effects of cue type and articulatory suppression in the random task cuing paradigm. Acta Psychologica, 115, 123-142.

Morin, A. (2002). Right hemispheric self-awareness: a critical assessment. Consciousness and Cognition, 11, 396-401.

Morin, A. (2006). Levels of consciousness and self-awareness: a comparison and integration of various neurocognitive views. Conscious and cognition, $15(2), 358-371$

Morin, A., \& Everett, J. (1990). Inner speech as a mediator of self-awareness, self-consciousness, and self-knowledge: an hypothesis. New Ideas in Psychology, 8(3), 337-356.

Piaget, J. (1959). A linguagem e o pensamento da criança (M. Campos, Trad.). Rio de Janeiro: Fundo de Cultura. (Original publicado em 1923)

Piaget, J. (1967). O raciocínio na criança (V. R. Chaves, Trad.). Rio de Janeiro: Record. (Original publicado em 1924)

Peirce, C. S. (1931-1958). Collected Papers of C. S. Peirce (Vols. 1-8; C. Hartshorne, P. Weiss, \& A. Burks, Orgs.). Cambridge: Harvard University Press.

Platão (1972). Sofista. (J. Paleikat \& J. C. Costa, Trads.). São Paulo: Abril Cultural. (Original publicado aproximadamente em 400 a.C.)

Raven, J. C. (1965). Matrizes progressivas - Escala Avançada. (F. Campos, Trad.). Rio de Janeiro: Centro Editor de Psicologia Aplicada.

Schneider, J. F. (2002). Relations among self-talk, self-consciousness, and selfknowledge. Psychological Reports, 91, 807-812.

Siegrist, M. (1995). Inner speech as a cognitive process mediating selfconsciouness and inhibiting self-deception. Psychological Reports, 76, 259-265.

Sokolov, A. N. (1972). Inner speech and thought (G. T. Onischenko, Trad.). New York: Plenum Press.

Teixeira, M. A. P., \& Gomes, W. B. (1995). Self-consciousness scale: a brazilian version. Psychological Reports, 77, 423-427.

Trapnell, P. D., \& Campbell, J. D. (1999). Private self-consciousness and the Five-Factor Model of Personality: distinguishing rumination from reflection. Journal of Personality and Social Psychology, 76(2), 284-304.

Vygotsky, L. S. (1986). Thought and Language (A. Kozulin, Trad.). Cambridge: MIT Press. (Original publicado em 1934)

Vygotsky, L. S. (1998). Child Psychology. In R. Rieber (Org.), The collected works of L. S. Vygotsky (Vol. 5, pp. 167-184). New York: Plenum Press.

Vygotsky, L. S., \& Luria, A. R. (1993). Studies on the history of behavior: ape, primitive, and child (V. Golod \& J. Knox, Trads.). New Jersey: Lawrence Erlbaum. (Original publicado em 1930)

Wiley, N. (1994). The semiotic self. Chicago: The University of Chicago Press. Wiley, N. (2006). Pragmatism and the dialogical self. International Journal for Dialogical Science, 1(1), 5-21.

Zanon, C., \& Teixeira, M. A. P. (2006). Adaptação do Questionário de Ruminação e Reflexão (QRR) para estudantes universitários brasileiros. Interação, 10, 75-82. 
1. Tradução dos autores.

2. Segue-se, neste estudo, a convenção de citar a Peirce através da grafia "CP [x.xxx]", referente a volume e parágrafo em The Collected papers of Charles S. Peirce (1931-58).

3. Utiliza-se a tradução das citações como aparecem em Wiley (1996).

Amanda da Costa DaSilveira, mestre em Psicologia Universidade Federal do Rio Grande do Sul, é doutoranda em Psicologia na mesma instituição. Endereço para correspondência: Rua Jacicoema, 492, Guarujá, Porto Alegre-RS. CEP: 91770-420. Telefone/Fax: (51) 3308-5115. E-mail: amandadacosta@gmail.com Mariane Lima DeSouza, doutora em Psicologia do Desenvolvimento Universidade Federal do Rio Grande do Sul, é professora adjunta no Departamento de Psicologia Social e do Desenvolvimento e no Programa de Pós-graduação em Psicologia da Universidade Federal do Espírito Santo. E-mail: limasouza@gmail.com William B. Gomes, doutor em Higher Education pela Southern Illinois University Carbondale, é professor associado no Instituto de Psicologia e no Programa de Pós-Graduação em Psicologia da Universidade Federal do Rio Grande do Sul. E-mail: gomesw@ufrgs.br 